\section{Antimicrobial resistance-a global challenge that deserves more attention!}

\author{
András Süle (1) 1,2
}

The continued aggravation of antibiotic resistance is a widely recognised major public health issue all around the world. According to the European Commission, every year more than 600000 infections occur, of which 25000 patients die in the European Union as a result of resistant bacteria; globally the number of deaths could be as high as 700000 per year. ${ }^{1}$ Meanwhile, the situation is feared to be intensified by the almost 50\% increase in global antibiotic consumption since the year $2000 .^{2}$

During these last decades, a dramatic increase has been observed in the ability of microorganisms to withstand antimicrobial treatments aimed against them. As a consequence, therapeutic options for infections caused by resistant bacteria are becoming limited. For patients, these persistent infections also result in longer hospital stays, a further increased risk of hospital-acquired additional infections, a higher overall burden on health systems, and an increased risk of spreading the infection to others.

A WHO assessment warns that, unless effective action is taken against antimicrobial resistance, a death toll of 10 million each year is foreseen by 2050, with a shattering effect on the world economy forcing up to 24 million people into extreme poverty worldwide by $2030 .^{3}$ It is also to be appreciated that should multiple essential medicines become ineffective, both economic and public health implications will be dreadful for current

\footnotetext{
'Department of Pharmacy, Peterfy KorhazRendelointezet es Manninger Jeno Orszagos Traumatologiai Intezet, Budapest, Hungary ${ }^{2}$ European Association of Hospital Pharmacists, Brussels, Belgium
}

Correspondence to Dr András Süle, Department of Pharmacy, Peterfy Korhaz-Rendelointezet es Manninger Jeno Orszagos Traumatologiai Intezet, Budapest, Hungary; andras.sule@eahp.eu and future generations, with antimicrobial resistance spiralling out of control.

Since the COVID-19 pandemic, however, the problems caused by antimicrobial resistance have moved out of the limelight. To amplify awareness of the European Antibiotic Awareness Day (EAAD)—which takes place every year on 18 November-the European Association of Hospital Pharmacists decided to dedicate the March issue of the European Journal of Hospital Pharmacy to antimicrobial resistance, a topic that also ranks highly in the association's policy and educational priorities.

This themed issue highlights the importance of practical and policy measures to combat the problem, focusing on infection prevention, responsible use of antibiotics, and antimicrobial stewardship, including surveillance and epidemiology dimensions. The articles in this issue also demonstrate why real-world data are crucial to accentuate the fact that patients in the everyday clinical setting usually present with multifactorial problems that most often require multi-professional approaches, especially in cases of complicated infections. When dealing with a polymicrobial disease (eg, severe trauma, postoperative sepsis, acute abdominal crises or diabetic foot syndrome), targeted, narrow-spectrum treatment options often fail to yield proper results, while choosing the broadspectrum route might easily contribute to the widespread emergence of antimicrobial resistance.

These cases underline the importance of pharmacists' involvement in frontline patient care within hospitals. Confident knowledge of pharmacokinetics and dynamics is key to determining the appropriate treatment strategies, including dosage, duration and frequency of administered antimicrobials, while also taking into account patients' liver and kidney functions and their effects on drug metabolism, elimination, response and toxicity.

In conclusion, it is imperative to take significant short-, middle- and long-term actions to improve awareness and understanding of antimicrobial resistance both within the healthcare setting, but also among patients and carers as well. Pharmacists' involvement in frontline clinical roles is essential at all levels of the healthcare system, as patients rarely present with singular concerns, especially in relation to chronic diseases and severe acute situations. Those inherently complex problems require equally complex therapeutic approaches where pharmacy expertise is crucial.

Through this approach, the main goal of safe, effective, responsibly used, quality assured and accessible treatments of infectious diseases is achievable for all patients who need them.

\section{Twitter András Süle @AndrasSule}

Funding The authors have not declared a specific grant for this research from any funding agency in the public, commercial or not-for-profit sectors.

\section{Competing interests None declared.}

Provenance and peer review Commissioned; internally peer reviewed.

(c) European Association of Hospital Pharmacists 2022. No commercial re-use. See rights and permissions. Published by BMJ.

$$
\text { A Check for updates }
$$

To cite Süle A. Eur J Hosp Pharm 2022;29:65.

Eur J Hosp Pharm 2022;29:65.

doi:10.1136/ejhpharm-2021-003207

ORCID iD

András Süle http://orcid.org/0000-0002-5760-9349

\section{REFERENCES}

1 Factsheet - AMR: a major European and Global challenge. Available: https://eceuropaeu/health/ sites/default/files/antimicrobial_resistance/docs/ amr_2017_factsheetpdf

2 Global antibiotic consumption and usage in humans, 2000-18: a spatial modelling study. Available: https://doi.org/10.1016/S2542-5196(21) 00280-1

3 New report calls for urgent action to avert antimicrobial resistance crisis. Available: https:// www.who.int/news/item/29-04-2019-new-report calls-for-urgent-action-to-avert-antimicrobialresistance-crisis 